\title{
INTRAVESICAL MIGRATION OF INTRAUTERINE CONTRACEPTIVE DEVICE
}

\author{
Mannan A $^{1}$, Adhikari D $\mathbf{B}^{1}$, Chughtai $\mathbf{M ~ N}^{1}$
}

30 Years old lady was referred from Gynaecology Department with six months history of burning micturition, urgency \& haematuria. Patient was 12 weeks pregnant at the time of presentation, inspite of IUCD insertion two and half years back at a Family Planning Centre. Her physical examination revealed no positive findings. Urine examination showed pyuria \& haematuria. Patient was carrying a plain radiograph which revealed a calcified mass measuring $1.5 \times 1.5-\mathrm{cm}$ in the pelvis overlying one limb of Copper T [fig.1]. Ultrasonography of pelvis

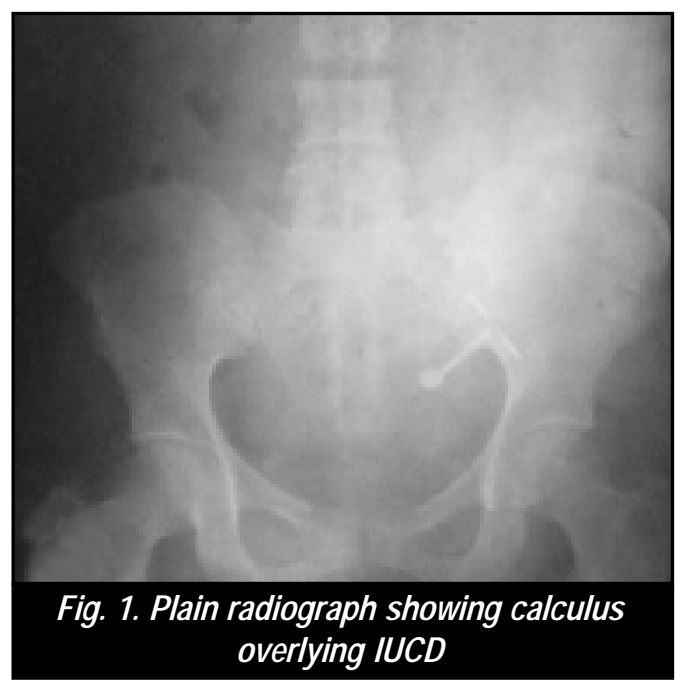

confirmed the presence of a calculus in the bladder.

Cystoscopy under local anaesthesia showed a calculus fixed to the left lateral wall of urinary bladder. Calculus was crushed with stone punch which uncovered one limb of copper T. Cross arms of IUCD were outside the bladder. It was pulled intact with foreign body forceps endoscopically [fig.2]. Postoperatively Foley catheter was retained for two days. Patient recovered completely from symptoms.

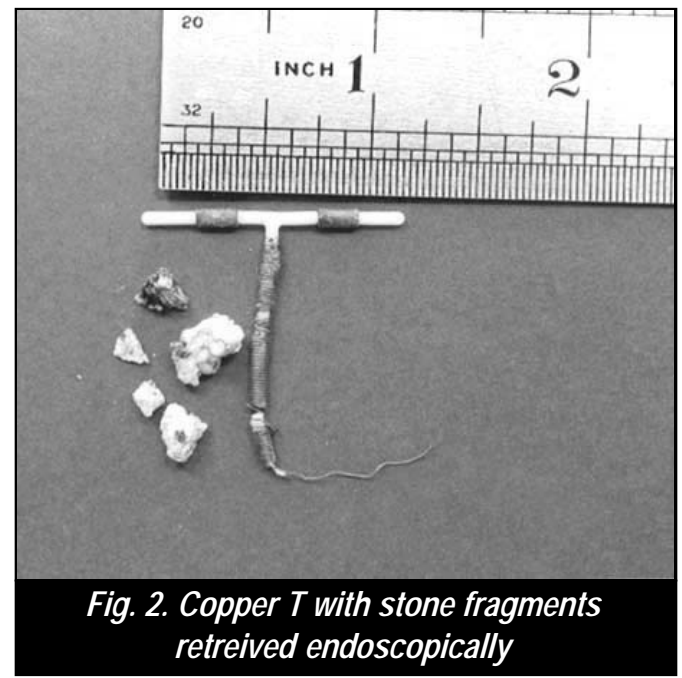

1. Dept. of Urology, Services Hospital, Postgraduate Medical Institute, Lahore, Pakistan.

Address for correspondence : Dr. Abdul Mannan, Assistant Professor of Urology,

Services Hospital, Postgraduate Medical Institute

Lahore, Pakistan.

Email: dadhikari@enet.wlink.np, dadhikari@hotmail.com 


\section{COMMENT}

Intrauterine contraceptive devices are being widely used in the developing countries. Their efficacy is close to tubal sterilization. It is generally a safe modality for long term contraception. Associated complications are bleeding, infection, ectopic pregnancy \& uterine perforation. Incidence of perforation has markedly reduced with the introduction of modern copper containing devices. Perforations are closely related to timing, technique $\&$ type of IUCD. Common places of migration are peritoneum, omentum, colon \& urinary bladder. Migration into bladder is extremely rare, only 19 such cases have been reviewed in the literature. ${ }^{1}$

Mechanism of bladder perforation is either primary i.e. at the time of insertion or secondary by slow migration across the walls of uterus \& bladder. Most of the perforations take place at the time of insertion and go unnoticed. Delayed onset of symptoms supports secondary migration. ${ }^{2}$ Dietrick and associates have reported one case of intravesical migration of IUCD which became symptomatic sixteen years after insertion. ${ }^{1}$ Asymptotic migrated IUCDs should also be retrieved to avoid dreadful complications like pelvic abscess, bowel or bladder perforation.

Encrustations and stone formation over IUCD in the bladder are not uncommon, however,duration of stone formation is variable. Most of the patients with migrated IUCD in the bladder present with irritative voiding symptoms and haematuria of variable duration. Diagnosis can be made with the help of Ultrasound and confirmed by cystoscopy. Small calculi over IUCD can be managed endoscopically whereas bigger ones require cystolithotomy. If IUCD is partially visible in the bladder and its threads are visible per vaginum, it can be pulled vaginally. ${ }^{3}$

Intravesical migration of IUCD is exceptionally rare but it must be kept in mind in women with recurrent urinary tract symptoms using IUCDs. Routine follow up can allow early detection of perforation.

\section{REFERENCES}

1. Dietrick DD, Issa MM, Kabalin JN and Bassett JB. Intravesical migration of intra uterine device. JUrol 1992; 147: 132-134,

2. El-Diasty TA, Shokeir AA, El-GharibMS, Sherif IS\& Sharmaa MA. Bladder stone: A complication of intravesical migration of Lippes loop. Scand J Urology Nephrology1993; 27: 279-280,

3. Kilholma P, Makinen J \& Vuori J. Bladder perforation: Uncommon complication with a misplaced IUD. Advances in contraception, 1989; 5: 47-49. 